\title{
SALMONELLA INFECTION IN HEALTHY PET REPTILES: BACTERIOLOGICAL ISOLATION AND STUDY OF SOME PATHOGENIC CHARACTERS
}

\author{
FABRIZIO BERTELlONI $^{1}$, MARIANNE CHEMALY ${ }^{2}$, DOMENICO CERri ${ }^{1}$, \\ FRANÇOISE LE GALL ${ }^{2}$ and VALENTINA VIRGINIA EBANI ${ }^{1 *}$ \\ ${ }^{1}$ Department of Veterinary Science, University of Pisa, Pisa, Italy \\ ${ }^{2}$ Anses, Ploufragan/Plouzané Laboratory, Hygiene and Quality of Poultry and Pork \\ Products Unit, France
}

(Received: 29 January 2016; accepted: 14 April 2016)

The fecal samples from 213 captive reptiles were examined, and 29 (13.61\%) Salmonella enterica isolates were detected: 14/62 (22.58\%) from chelonians, 14/135 $(10.37 \%)$ from saurians, and 1/16 (6.25\%) from ophidians. The isolates were distributed among 14 different serotypes: Miami, Ebrie, Hermannsweder, Tiergarten, Tornov, Pomona, Poona, Goteborg, Abaetetube, Nyanza, Kumasi, Typhimurium, 50:b: $\mathrm{z}_{6}, 9,12: \mathrm{z}_{29}: 1,5$, and a non-motile serotype with antigenic formula 1,4,[5],12:-:-. Salmonella typhimurium and 50:b: $\mathrm{z}_{6}$ isolates showed the $s p v$ plasmid virulence genes, responsible of the capability to induce extra-intestinal infections. In some cases, pulsed field gel electrophoresis revealed different profiles for the strains of the same serotypes, showing different origins, whereas a common source of infection was supposed when one pulsotype had been observed for isolates of a serovar. Twentyseven $(93.10 \%)$ isolates showed resistance to one or more antibiotics. Ceftazidime was active to all the tested isolates, whereas the highest percentages of strains were no susceptible to tigecycline $(93.10 \%)$, streptomycin $(89.66 \%)$, and sulfonamide $(86.21 \%)$.

Keywords: Salmonella, pet reptiles, antimicrobial resistance, PFGE, virulence genes, serotype 1,4,[5],12:-:-

\section{Introduction}

Salmonellosis is known to be one of the most important causes of public health concern worldwide. In Europe, during 2013, a total of 82,694 confirmed cases of human salmonellosis were reported, with 59 deaths due to non-typhoidal Salmonella [1].

*Corresponding author; E-mail: valentina.virginia.ebani@unipi.it 
Most of the human cases resulted from consumption of foods of animal origin contaminated with salmonellae. However, several cases of infection due to salmonellae shed from animals, including pet reptiles, are reported.

In the past years, exotic animals, mainly reptiles, were more often searched as companion pets, resulting in a great trade and movement of non-conventional species all around the world. Recent data revealed that Europe is the first reptiles' importer in the world [2]. Reptiles are often asymptomatic carriers of some important pathogenic bacteria [3-5]. In particular, several studies showed that cold-blooded animals are direct or indirect source of salmonellae in human infection outbreaks [6-11].

Salmonellae isolated from wild and captive reptiles mainly belong to Salmonella enterica subsp. salamae, arizonae, diarizonae, indica, houtenae, and Salmonella bongori, even though cases of infection by S. enterica subsp. enterica are reported in these animals [12].

Some Salmonella serovars are probably commensal organisms in reptiles and retain their pathogenicity for warm-blooded animals [13].

The aims of the present investigation were: (1) to determine the prevalence of Salmonella spp. excreted in feces of clinically healthy pet reptiles, (2) to verify the presence of plasmid virulence genes in the isolates, (3) to study genetic profiles of the isolates by PFGE, and (4) to determine the susceptibility of the isolates to antibiotics.

\section{Materials and Methods}

\section{Bacteriological examinations}

During the period 2011-2012, 213 feces samples from captive reptiles (135 saurians, 62 chelonians, and 16 ophidians) were collected in a pet shop. All tested animals have been imported during the last 4 weeks before sampling; they had no contact with each other in the pet shop, but no data were available about their conditions during the travel.

Each sample was collected into an aseptic tube from individual cages and pools and delivered refrigerated, as soon as possible, to the Bacteriology Laboratory of the Department of Veterinary Science, University of Pisa. Samples were kept at $4{ }^{\circ} \mathrm{C}$ for a maximum of $4 \mathrm{~h}$ before processing in the laboratory.

Salmonella spp. isolation was carried out as previously described [14]. Briefly, about $3 \mathrm{~g}$ of feces was incubated in $10 \mathrm{ml}$ of buffered peptone water at $37^{\circ} \mathrm{C}$ for $24 \mathrm{~h}$. About $1 \mathrm{ml}$ of this culture was transferred to $10 \mathrm{ml}$ of Selenite broth 
(Difco, Becton Dickinson, Sparks, MD, USA) and $10 \mathrm{ml}$ of Rappaport-Vassiliadis broth (Difco) and the tubes were incubated at $42{ }^{\circ} \mathrm{C}$ for $24 \mathrm{~h}$. One loopful from each broth culture was streaked onto duplicate plates of Brilliant Green Agar (Difco) and Salmonella-Shigella Agar (Difco), and the plates were incubated at $37^{\circ} \mathrm{C}$ for $24 \mathrm{~h}$. Suspected colonies were inoculated into tubes containing Triple Sugar Iron Agar (Oxoid Ltd., Basingstoke, UK) which were incubated at $37{ }^{\circ} \mathrm{C}$ for $24 \mathrm{~h}$.

Isolates with biochemical profile reportable to Salmonella spp. were serotyped according to the Kaufmann-White Salmonella serotyping scheme [15] with polyvalent and monovalent somatic $(\mathrm{O})$ and flagella $(\mathrm{H})$ antisera (Bio-Rad, Marnes la Coquette, France).

\section{Pulsed field gel electrophoresis (PFGE) typing}

To verify if the isolates of the same serotype belonged to the same strain, PFGE was performed. PFGE was carried out with a CHEF-DR III system (Bio-Rad) on DNA of each Salmonella isolate previously treated with $X b a I$ restriction endonuclease, according to the standardized Salmgene and PulseNet protocol [16, 17]. Gels were stained with Gel-Red; DNA-banding patterns were visualized under UV light and captured using the Gel Doc Eq system and Quantity One software (Bio-Rad). DNA patterns were analyzed with BioNumerics software (V 4.1, Applied Maths, Kortrijk, Belgium). Algorithms available within the program were used to compare the patterns. Dendrograms were produced, using the Dice coefficient and the unweighted pair group method with arithmetic averages, with a $1 \%$ tolerance limit and $1 \%$ optimization.

\section{Detection of plasmid virulence genes}

The presence of plasmid virulence genes $(s p v C, s p v B$, and $s p v R)$ was determined using PCR assays which amplified fragments of $235 \mathrm{bp}, 717 \mathrm{bp}$, and 202 bp, respectively [18, 19].

DNA was extracted from each Salmonella isolate using the DNeasyBlood and Tissue Kit (Qiagen, GmbH, Hilden, Germany) following the manufacturer's instructions. Each PCR assay was performed in a reaction volume of $50 \mu \mathrm{l}$ consisting of $200 \mu \mathrm{M}$ each dATP, dTTP, dCTP, and dGTP, $0.5 \mu \mathrm{M}$ of each primer, 1.25 U of Taq polymerase (Qiagen), $5 \mu$ of 10× Qiagen PCR buffer, and $2 \mu \mathrm{l}$ of extracted DNA. All the amplification products were analyzed by electrophoresis on $1.5 \%$ agarose gel at $100 \mathrm{~V}$ for $45 \mathrm{~min}$; gel was stained with ethidium 
bromide and observed. GelPilot 100 bp Plus Ladder (Qiagen) was used as DNA marker.

Presence of Phase I and Phase II flagella genes

Five non-motile isolates with the antigenic formula 1,4,[5],12:-:- were submitted to PCR assays to verify the presence of fliC gene, encoding for Phase I flagella, $f j B$ gene, encoding the Phase II flagella [20].

Antimicrobial susceptibility test

Salmonella isolates were submitted to the standard disk diffusion method of Kirby-Bauer [21] on Mueller Hinton Agar (Oxoid). The following antimicrobial molecules (Oxoid) were tested: amoxicillin-clavulanic acid (AMC; $30 \mu \mathrm{g}$ ), ampicillin (AMP; $10 \mu \mathrm{g}$ ), amikacin (AK; $30 \mu \mathrm{g}$ ), cephalothin (KF; $30 \mu \mathrm{g})$, cefotaxime (CTX; $30 \mu \mathrm{g})$, ceftazidime (CAZ; $30 \mu \mathrm{g})$, chloramphenicol (C; $30 \mu \mathrm{g})$, ciprofloxacin (CIP; $5 \mu \mathrm{g}$ ), colistin (CT; $10 \mu \mathrm{g}$ ), enrofloxacin (ENR; $5 \mu \mathrm{g}$ ), florfenicol (FFC; $30 \mu \mathrm{g})$, gentamicin $(\mathrm{CN} ; 10 \mu \mathrm{g})$, kanamycin $(\mathrm{K} ; 30 \mu \mathrm{g})$, nalidixic acid (NA; $2 \mu \mathrm{g}$ ), nitrofurantoin (F; $300 \mu \mathrm{g}$ ), streptomycin (S; $10 \mu \mathrm{g})$, sulfamethoxazole-trimethoprim (STX; $25 \mu \mathrm{g}$ ), sulfonamide (S3; $300 \mu \mathrm{g}$ ), tetracycline (TE; $30 \mu \mathrm{g})$, tigecycline (TGC; $15 \mu \mathrm{g}$ ), tobramycin (TOB; $10 \mu \mathrm{g}$ ), and trimethoprim (W; $5 \mu \mathrm{g}$ ).

For each isolate, the zone of inhibition around each disk was measured, after incubation at $37{ }^{\circ} \mathrm{C}$ for $24 \mathrm{~h}$. Results were interpreted following EUCAST breakpoint tables and, where not possible, according to NCCLS indications $[22,23]$ : the isolates were classified as susceptible (S), intermediate (I), and resistant $(\mathrm{R})$.

\section{Results}

\section{Bacteriological examinations}

From the 213 fecal samples, 29 (13.61\%) S. enterica isolates were detected. In particular, $14 / 62(22.58 \%)$ of the chelonians, $14 / 135(10.37 \%)$ of the saurians, and $1 / 16(6.25 \%)$ of the ophidians were positive.

The $29 \mathrm{~S}$. enterica isolates were distributed among 14 different serotypes. Table I shows the results in relation to species and number of animals examined. 
Table I. Salmonella enterica serotypes isolated from feces samples of reptiles in relation to animal species

\begin{tabular}{|c|c|c|c|c|}
\hline Category & Animal species & $\begin{array}{c}\text { Number of } \\
\text { examined } \\
\text { animals }\end{array}$ & $\begin{array}{c}\text { Number of } \\
\text { positive } \\
\text { animals (\%) }\end{array}$ & $\begin{array}{c}\text { Salmonella enterica } \\
\text { subspecies } \\
\text { and serotypes } \\
\text { (number of isolates) }\end{array}$ \\
\hline \multirow{11}{*}{ Chelonians } & Chrysemys concinna & 1 & 0 & \\
\hline & Chrysemys picta & 1 & 0 & \\
\hline & Geochelone carbonaria & 1 & 0 & \\
\hline & Pseudemys concinna & 1 & 0 & \\
\hline & & & & $\begin{array}{c}\text { I Miami (5) } \\
\text { I 1,4,5,12:-:- (4) }\end{array}$ \\
\hline & Testudo hermanni hermanni & 30 & $13(43.33)$ & $\begin{array}{c}\text { I Hermannsweder (2) } \\
\text { I Goteborg (1) } \\
\text { II } 9,12: \mathrm{z}_{29}: 1,5 \text { (1) }\end{array}$ \\
\hline & Testudo hermanni boettgeri & 12 & $1(8.33)$ & I 1,4,5,12:-:- (1) \\
\hline & Trachemys scripta elegans & 14 & 0 & \\
\hline & Trachemys scripta scripta & 2 & 0 & \\
\hline & Eublepharis macularius & 1 & 0 & \\
\hline & Gerrhosaurus major & 1 & 0 & \\
\hline \multirow{6}{*}{ Saurians } & Iguana iguana & 96 & $7(7.29)$ & $\begin{array}{l}\text { I Ebrie (3) } \\
\text { I Abaetetube (1) } \\
\text { I Nyanza (1) } \\
\text { I Kumasi (1) } \\
\text { II 50:b:z6 (1) }\end{array}$ \\
\hline & Oplurus cyclurus & 2 & 0 & \\
\hline & Paroedura pictus & 4 & 0 & \\
\hline & Physignathus cocincinus & 13 & $5(38.46)$ & $\begin{array}{l}\text { I Tiergarten (2) } \\
\text { I Pomona (2) } \\
\text { I Tornov (1) }\end{array}$ \\
\hline & Pogona vitticeps & 5 & $1(20.00)$ & I Tornov (1) \\
\hline & Tiliqua scincoides & 1 & 0 & \\
\hline \multirow{8}{*}{ Ophidians } & Tupinambis merianae & 3 & 0 & \\
\hline & Chamaeleo verrucosus & 9 & $1(11.11)$ & I Poona (1) \\
\hline & Boa constrictor & 1 & 0 & \\
\hline & Elaphe guttata & 3 & 0 & \\
\hline & Lampropeltis triangulum & 1 & 0 & \\
\hline & Python molurus & 2 & 0 & \\
\hline & Python regius & 9 & $1(11.11)$ & I Typhimurium (1) \\
\hline & Total & 213 & $29(13.61)$ & \\
\hline
\end{tabular}

Note: I = Salmonella enterica subsp. enterica, II = Salmonella enterica subsp. salamae.

The serovars most frequently encountered were Miami (5 isolates from tortoises Testudo hermanni hermanni), 1,4,[5],12:-:- (4 isolates from Testudo hermanni hermanni and 1 from Testudo hermanni boettgeri), Ebrie (3 isolates from Iguana iguana), Hermannsweder (2 isolates from Testudo hermanni hermanni), 
Pomona ( 2 isolates from Physignathus cocincinus), Tiergarten (2 isolates from Physignathus cocincinus), and Tornov (1 isolate from Physignathus cocincinus and 1 from Pogona vitticeps).

One strain of Typhimurium was isolated from a Python regius.

\section{PFGE typing}

PFGE analysis revealed dissimilar situations for the different serotypes.

The five 1,4,[5],12:-:- isolates showed the same profile. The five Miami isolates presented three different pulsotypes, with three isolates identical and the other two with different profiles.

Only one pulsotype was identified for each of the serotypes Ebrie, Hermannsweder, and Tornov, respectively. Different profiles were found for the two Pomona and two Tiergarten isolates, respectively.

\section{Detection of plasmid virulence genes}

Among the investigated isolates, the strain Typhimurium and the strain 50:b:z6 showed the $s p v C, \operatorname{spvB}$, and $s p v R$ plasmid virulence genes.

Presence of genes encoding for Phase I and Phase II flagella

PCR assay detected the presence of $f l i C$ and $f j B$ genes encoding the first and the second flagellar phases, respectively, in the five non-motile isolates tested.

\section{Antimicrobial susceptibility test}

The results of the antimicrobial susceptibility tests are shown in Table II. Twenty-seven $(93.10 \%)$ isolates were resistant to one or more antibiotics, and 20 (68.96\%) were multiresistant.

Ceftazidime resulted as active to all the tested isolates. High percentages of sensitive Salmonella strains were observed with cephalosporins (93.10\%-100\%), penicillins (93.10\%-96.55\%), sulfonamide-trimethoprim (89.66\%-93.10\%), and quinolones $(82.76 \%-89.66 \%)$.

On the other hand, considering the isolates classified as resistant and intermediate, the highest percentages of strains resulted non-susceptible to tigecycline $(93.10 \%)$, streptomycin $(89.66 \%)$, and sulfonamide $(86.21 \%)$. 
Table II. Number of Salmonella enterica isolates susceptible, intermediate, and resistant to the antimicrobial agents tested

\begin{tabular}{|c|c|c|c|c|c|c|c|c|}
\hline \multirow[t]{2}{*}{ Antibiotics } & \multicolumn{2}{|c|}{ Susceptible } & \multicolumn{2}{|c|}{ Intermediate } & \multicolumn{2}{|c|}{ Resistant } & \multicolumn{2}{|c|}{$\begin{array}{c}\text { Non-susceptible: } \\
\text { intermediate+ } \\
\text { resistant }\end{array}$} \\
\hline & $\begin{array}{c}\text { Number of } \\
\text { isolates }\end{array}$ & $\%$ & $\begin{array}{c}\text { Number of } \\
\text { isolates }\end{array}$ & $\%$ & $\begin{array}{c}\text { Number of } \\
\text { isolates }\end{array}$ & $\%$ & $\begin{array}{c}\text { Number of } \\
\text { isolates }\end{array}$ & $\%$ \\
\hline \multicolumn{9}{|l|}{ Quinolones } \\
\hline NA & 24 & 82.76 & 2 & 6.90 & 3 & 10.34 & 5 & 17.24 \\
\hline CIP & 26 & 89.66 & 3 & 10.34 & 0 & 0.00 & 3 & 10.34 \\
\hline ENR & 24 & 82.76 & 3 & 10.34 & 2 & 6.90 & 5 & 17.24 \\
\hline \multicolumn{9}{|l|}{ Penicillin } \\
\hline AMP & 27 & 93.10 & 0 & 0.00 & 2 & 6.90 & 2 & 6.90 \\
\hline $\mathrm{AMC}$ & 28 & 96.55 & 0 & 0.00 & 1 & 3.45 & 1 & 3.45 \\
\hline \multicolumn{9}{|c|}{ Cephalosporins } \\
\hline CTX & 27 & 93.10 & 2 & 6.90 & 0 & 0.00 & 2 & 6.90 \\
\hline $\mathrm{KF}$ & 28 & 96.55 & 0 & 0.00 & 1 & 3.45 & 1 & 3.45 \\
\hline CAZ & 29 & 100 & 0 & 0.00 & 0 & 0.00 & 0 & 0.00 \\
\hline \multicolumn{9}{|c|}{ Aminoglycoside } \\
\hline $\mathrm{CN}$ & 22 & 75.86 & 7 & 24.14 & 0 & 0.00 & 7 & 24.14 \\
\hline $\mathrm{K}$ & 8 & 27.59 & 21 & 72.41 & 0 & 0.00 & 21 & 72.41 \\
\hline $\mathrm{S}$ & 3 & 10.34 & 23 & 79.31 & 3 & 10.34 & 26 & 89.66 \\
\hline $\mathrm{AK}$ & 19 & 65.52 & 9 & 31.03 & 1 & 3.45 & 10 & 34.48 \\
\hline TOB & 18 & 62.07 & 8 & 27.59 & 3 & 10.34 & 11 & 37.93 \\
\hline \multicolumn{9}{|c|}{ Tetracyclines } \\
\hline $\mathrm{TE}$ & 7 & 24.14 & 14 & 48.28 & 8 & 27.59 & 22 & 75.86 \\
\hline TGC & 2 & 6.90 & 12 & 41.38 & 15 & 51.72 & 27 & 93.10 \\
\hline \multicolumn{9}{|c|}{ Sulfonamide-trimethoprim } \\
\hline $\mathrm{S} 3$ & 4 & 13.79 & 1 & 3.45 & 24 & 82.76 & 25 & 86.21 \\
\hline W & 26 & 89.66 & 1 & 3.45 & 2 & 6.90 & 3 & 10.34 \\
\hline SXT & 27 & 93.10 & 2 & 6.90 & 0 & 0.00 & 2 & 6.90 \\
\hline \multicolumn{9}{|l|}{ Others } \\
\hline $\mathrm{CT}$ & 27 & 93.10 & 1 & 3.45 & 1 & 3.45 & 2 & 6.90 \\
\hline $\mathrm{F}$ & 16 & 55.17 & 7 & 24.14 & 6 & 20.69 & 13 & 44.83 \\
\hline $\mathrm{C}$ & 24 & 82.76 & 5 & 17.24 & 0 & 0.00 & 5 & 17.24 \\
\hline FFC & 23 & 79.31 & 6 & 20.69 & 0 & 0.00 & 6 & 20.69 \\
\hline
\end{tabular}

Note: $\quad \mathrm{AMC}=$ amoxicillin-clavulanic acid, $\mathrm{AMP}=$ ampicillin, $\mathrm{AK}=$ amikacin, $\mathrm{KF}=$ cephalothin, $\mathrm{CTX}=$ cefotaxime, $\mathrm{CAZ}=$ ceftazidime, $\mathrm{C}=$ chloramphenicol, $\mathrm{CIP}=$ ciprofloxacin, $\mathrm{CT}=$ colistin, $\mathrm{ENR}=$ enrofloxacin, $\mathrm{FFC}=$ florfenicol, $\mathrm{CN}=$ gentamicin, $\mathrm{K}=$ kanamycin, $\mathrm{NA}=$ nalidixic acid, $\mathrm{F}=$ nitrofurantoin, $\mathrm{S}=$ streptomycin, $\mathrm{STX}=$ sulfamethoxazole-trimethoprim, $\mathrm{S} 3=$ sulfonamide, $\mathrm{TE}=$ tetracycline, $\mathrm{TGC}=$ tigecycline, $\mathrm{TOB}=$ tobramycin, $\mathrm{W}=$ trimethoprim 


\section{Discussion}

The results obtained during the present investigation confirm that captive reptiles are important reservoirs of salmonellae and represent a source of infection for humans. Chelonians, in particular terrestrial turtles, which are the reptiles most commonly present in domestic environment, seem to be infected most frequently than the other cold-blooded animals. The examined Testudo hermanni shed salmonellae belonging to several serotypes: Miami, Hermannsweder, Goteborg, 9,12: $\mathrm{Z}_{29}: 1,5$, and the non-motile $1,4,[5], 12:-:-$.

Several serotypes were also detected among saurians, in particular from iguanas Iguana iguana and water dragons Physignathus cocincinus, which were the most numerous animals tested. Serotypes encountered in these reptiles are not frequently isolated from warm-blooded animals, and a few data about their spreading among humans and animals are available in the literature, except for Salmonella abaetetuba which has been previously detected in wild iguanas and geckos [5], and has been associated to cases of human salmonellosis [24, 25].

A range of 14 different Salmonella serotypes was detected in the present survey. A predominant serotype was not encountered and host-specific association between certain Salmonella serotypes and some reptile species does not seem to exist, in accordance with the results obtained by other authors [26].

Salmonellae isolated during the present survey belonged to serotypes not frequently encountered in other animal species. In contrast with the results reported by other investigations that have commonly associated $S$. enterica subsp. houtenae and S. bongori with reptiles [27], the highest number of our detected isolates belonged to $S$. enterica subsp. enterica. Salmonellae of the subsp. enterica are the most frequently isolated from humans and warm-blooded animals and often associated to clinical forms; thus, these results underline the zoonotic risk of reptiles housed as pet animals.

Moreover, a Python regius allowed the isolation of $S$. Typhimurium that is considered as one of the most pathogenic serotypes for humans, mammals, and birds. This strain had the investigated virulence genes, confirming its pathogenic potential.

Among the other analyzed isolates, only S. enterica subsp. salamae 50:b:z6 had the $s p v$ virulence genes, suggesting that, as Typhimurium, it is maybe cause of intestinal and extra-intestinal infections. In fact, the $s p v$ virulence locus is required for sustained extra-intestinal infections and clinical disease through macrophage cytotoxicity and destabilization of the cytoskeleton of the eukaryotic cell. The absence of the $s p v$ virulence genes in the other studied isolates supports the hypothesis that extra-intestinal infections are scarce in reptiles [28]. 
Five strains, isolated from tortoises, were classified as a non-motile serotype with antigenic formula 1,4,[5],12:-:-.

The 1,4,[5],12:-:-strains were the most prevalent non-motile Salmonella spp. circulating in France during the period 2000-2009, even though they have been rarely reported in food, environment, or animals when compared with other serotypes $[29,30]$.

The genetic studies during the present investigation show that these isolates bring the genes for both Phase I and Phase II flagella, even though they did not express them in any cases. Previous studies considered the 1,4[5,],12:-:- strains as non-motile variant of $S$. Typhimurium. The presence of $f i C$ and $f l i B$ amplicons in the phenotypically non-motile isolates suggests that their expression should be blocked by mutation or deletion in the promoter regions linked to the flagellar phase expression [30].

Another atypical variant of $S$. Typhimurium is the monophasic 1,4,[5],12:i:strain, lacking the Phase II flagellar antigen, which has become increasingly important since the mid-1990s worldwide, including Italy [31].

The non-motile 1,4,[5],12:-:- strain has been rarely isolated and characterized, and in particular, no data are available in the literature about its presence in Italy. Its detection in captive reptiles confirms that cold-blooded animals, coming from exotic geographic areas, contribute to the introduction and spreading of new pathogens in the country of importation.

Habitat and diet components are generally considered as the origin of intestinal Salmonella in reptiles [26]. The origin of the salmonellae isolated in this survey is not clear because it is not possible to determine if the animals have contracted salmonellae in the country of exportation, during the traveling, in the sale center.

However, travel and new environments represent cause of stress for reptiles, favoring the fecal excretion of pathogens including salmonellae.

Several strains resulted resistant to one or more antibiotics. Among them, one Poona isolate was resistant to six antibiotics and four isolates (Ebrie, Tornow,

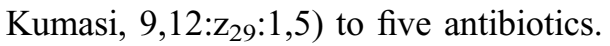

Ceftazidime was active to all the tested isolates, and most strains were sensitive to enrofloxacin, which are frequently used against salmonella infections [32].

Different values of resistance to aminoglycoside were observed. In fact, good results were obtained with gentamicin, with $75.86 \%$ of susceptible isolates, whereas streptomycin gave the $89.66 \%$ of non-susceptible strains. Resistance to streptomycin has been largely documented. Its extensive use, in particular in veterinary medicine, has contributed to the successful spread of resistance genes [33].

During the present study, great variability was found among the different aminoglycoside molecules tested, but this result could be related to the 
mechanisms of action of these antibiotics. All aminoglycoside molecules act primarily by impairing bacterial protein synthesis through binding to prokaryotic ribosomes. However, the site of action differs for individual molecules and resistance, associated to a numerous genes, more often develops against single molecules rather than all members of the class $[34,35]$.

A high percentage (93.10\%) of isolates resulted non-susceptible to tigecycline. This is a member of the glycylcycline group of antibiotics, and was registered in the EU in April 2006. It is a bacteriostatic antibiotic active against a broad range of bacteria, with only few naturally resistant exceptions (Proteus spp., Morganella morganii, Providencia spp., and Pseudomonas aeruginosa). Specifically, tigecycline is effective against multidrug resistant bacteria, including Enterobacteriaceae. Reports of resistance to tigecycline have been rare in naturally susceptible pathogens; however, resistant variants may be encountered [36].

Our results suggest that resistance to tigecycline is not so rare and it represents an emerging problem for the bacterial treatment in veterinary and human medicine, as supposed by other authors [37-39].

A high percentage $(75.86 \%)$ of isolates resulted non-susceptible to tetracycline too. This result is in agreement with those obtained by other authors, which found reduced efficacy of this antimicrobial against salmonellae, maybe because of the indiscriminate use in humans and animals therapy [40-42].

In some cases, PFGE showed different pulsotypes, when isolates belonging to the same serotype were compared. These results suggest that animals infected by the same Salmonella serotype have contracted the infection from different sources. In other cases, one pulsotype has been observed for the isolates of a same serotype (Ebrie, Tornov, and Hermannsweder) showing that they belong to a same strain and suggesting that they have been contracted from the same source.

All the five isolates belonging to the serotype 1,4,[5],12:-:- had the same PFGE profile, whereas the antimicrobial susceptibility test revealed three different resistotypes (S3, TGC-S3, TE-S3); these results suggest that the five non-motile isolates are different strains of a same cluster.

\section{Conclusion}

Pet reptiles may be important source of salmonellae for their owners. In particular, children, which share living space with indoor reptiles, result more susceptible than adult developing severe invasive disease [43]. Infected reptiles can transmit salmonellae to other household animals, such as dogs and cats, increasing the risk of exposure for humans. Reptiles are usually considered as 
fecal reservoirs of salmonellae able to cause only intestinal infections, but in some cases, they can excrete more pathogenic strains causing extra-intestinal forms.

Moreover, salmonellae excreted by cold-blooded vertebrates could be involved in the antibiotic resistance threat. In fact, these strains can be resistant to one or more antibiotics determining, in some cases, treatment failure; moreover, they can be a source of antimicrobial resistance genes for other bacteria. For this reason, the antimicrobial sensitivity test is essential in determining an appropriate antibiotic therapy that, anyway, should be accompanied by the correction of environmental and nutrition deficiencies.

\section{Conflict of Interest}

We declare that we have no conflict of interest.

\section{References}

1. EFSA and ECDC (European Food Safety Authority and European Centre for Disease Prevention and Control): The European Union summary report on trends and sources of zoonoses, zoonotic agents and food-borne outbreaks in 2013. EFSA J 13, 3991 (2015).

2. Bush, E. R., Baker, S. E., MacDonald, D. W.: Global trade in exotic pets 2006-2012. Conserv Biol 28, 663-676 (2014).

3. Ebani, V. V., Fratini, F., Bertelloni, F., Cerri, D., Tortoli, E.: Isolation and identification of mycobacteria from captive reptiles. Res Vet Sci 93, 1136-1138 (2012).

4. Giacomelli, M., Piccirillo, A.: Pet reptiles as potential reservoir of Campylobacter species with zoonotic potential. Vet Rec 174, 479-480 (2014).

5. Jimenez, R. R., Barquero-Calvo, E., Abarca, J. G., Porras, L. P.: Salmonella isolates in the introduced Asian House Gecko (Hemidactylusfrenatus) with emphasis on Salmonella weltevreden, in two regions in costa-Rica. Vector Borne-Dis 15, 550-555 (2015).

6. Cooke, F. J., De Pinna, E., Maguire, C., Guha, S., Pickard, D. J., Farrington, M., Threlfall, E. J.: First report of human infection with Salmonella enterica serovar Apapa resulting from exposure to a pet lizard. J Clin Microbiol 47, 2672-2674 (2009).

7. Harris, J. R., Bergmire-Sweat, D., Schlegel, J. H., Winpisinger, K. A., Klos, R. F., Perry, C., Tauxe, R. V., Sotir, M. J.: Multistate outbreak of Salmonella infections associated with small turtle exposure, 2007-2008. Pediatrics 124, 1388-1394 (2009).

8. Van Meervenne, E., Botteldoorn, N., Lokietek, S., Vatlet, M., Cupa, A., Naranjo, M., Dierick, K., Bertrand, S.: Turtle-associated Salmonella septicaemia and meningitis in a 2-month-old baby. J Med Microbiol 58, 1379-1381 (2009).

9. Lowther, S. A., Medus, C., Scheftel, J., Leano, F., Jawahir, S., Smith, K.: Foodborne outbreak of Salmonella subspecies IV infections associated with contamination from bearded dragons. Zoonoses Public Health 58, 560-566 (2011). 
10. Pees, M., Rabsch, W., Plenz, B., Fruth, A., Prager, R., Simon, S., Schmidt, V., Munch, S., Braun, P.: Evidence for the transmission of Salmonella from reptiles to children in Germany, July 2010 to October 2011. Euro Surveill 18. pii, 20634 (2013).

11. MetteeZarecki, S. L., Bennett, S. D., Hall, J., Yaeger, J., Lujan, K., Adams-Cameron, M., Winpisinger Quinn, K., Brenden, R., Biggerstaff, G., Hill, V. R., Sholtes, K., Garrett, N. M., Lafon, P. C., Barton Behravesh, C., Sodha, S. V., Salmonella typhimurium Outbreak Investigation Team: US outbreak of human Salmonella infections associated with aquatic frogs, 2008-2011. Pediatrics 131, 724-731 (2013).

12. Mermin, J., Hutwagner, L., Vugia, D., Shallow, S., Daily, P., Bender, J., Koehler, J., Marcus, R., Angulo, F. J.: Reptile, amphibians, and human Salmonella infection: A population-based, case-cohort study. Clin Infect Dis 38, 253-261 (2004).

13. Chiodini, R. J., Sundberg, J. P.: Salmonellosis in reptiles: A review. Am J Epidemiol 113, 494-499 (1981).

14. Ebani, V. V., Cerri, D., Fratini, F., Meille, N., Valentini, P., Andreani, E.: Salmonella enterica isolates from faeces of domestic reptiles and a study of their antimicrobial in vitro sensitivity. Res Vet Sci 78, 117-121 (2005).

15. Grimont, P. A. D., Weill, F. X.: Antigenic Formulae of the Salmonella Serovars, 9th Edition. WHO Collaborating Center for Reference and Research on Salmonella, Institut Pasteur, Paris, 2007, Available at http:/www.pasteur.fr/sante/clre/cadrecnr/salmoms/ WKLM_En.pdf.

16. Peters, T. M., Maguire, C., Threlfall, E. J., Fisher, I. S., Gill, N., Gatto, A. J.: Salm-gene project: The Salm-gene project - A European collaboration for DNA fingerprinting for food-related salmonellosis. Euro Surveill 8, 46-50 (2003).

17. Ribot, E. M., Fair, M. A., Gautom, R., Cameron, D. N., Hunter, S. B., Swaminathan, B., Barrett, T. J.: Standardization of pulsed-field gel electrophoresis protocols for the subtyping of Escherichia coli O157:H7, Salmonella, and Shigella for PulseNet. Foodborne Pathog Dis 3, 59-67 (2006).

18. Skyberg, J. A., Logue, C. M., Nolan, L. K.: Virulence genotyping of Salmonella spp. with multiplex PCR. Avian Dis 50, 77-81 (2006).

19. Parvathi, A., Vijayan, J., Murali, G., Chandran, P.: Comparative virulence genotyping and antimicrobial susceptibility profiling of environmental and clinical Salmonella enterica from Cochin, India. Curr Microbiol 62, 21-26 (2011).

20. Dauga, C., Zabrovskaia, A., Grimont, P. A.: Restriction fragment length polymorphism analysis of some flagellin genes of Salmonella enterica. J Clin Microbiol 36, 2835-2843 (1998).

21. Bauer, A., Kirby, W. M. N., Sherris, J. C., Turk, M.: Antibiotic susceptibility testing by a standardized single disc method. Am J Pathol 45, 493-496 (1966).

22. Clinical and Laboratory Standards Institute: Performance standards for antimicrobial susceptibility testing: Seventeenth Informational Supplement, Vol. 27. Clinical and Laboratory Standards Institute, Pennsylvania, USA, 2007.

23. EUCAST. The European Committee on Antimicrobial Susceptibility Testing. Breakpoint tables for interpretation of MICs and zone diameters, Version 3.1, 2013, http://www.eucast.org.

24. Woodward, D. L., Khakhria, R., Johnson, W. M.: Human salmonellosis associated with exotic pets. J Clin Microbiol 35, 2786-2790 (1997).

25. Franco, A., Hendriksen, R. S., Lorenzetti, S., Onorati, R., Gentile, G., Dell'Omo, G., Aarestrup, F. M., Battisti, A.: Characterization of Salmonella occurring at high prevalence 
in a population of the land iguana Conolophus subcristatus in Galapágos Islands, Ecuador. PLoS One 6, e 23147 (2011).

26. Briones, V., Téllez, S., Goyache, J., Ballesteros, C., del Pilar Lanzarot, M., Dominguez, L., Fernandez-Garayzabal, J. F.: Salmonella diversity associated with wild reptiles and amphibians in Spain. Environ Microbiol 6, 868-871 (2004).

27. Geue, L., Loschner, U.: Salmonella enterica in reptiles of German and Austrian origin. Vet Microbiol 84, 71-91 (2002).

28. Pasmans, F., Martel, A., Boyen, F., Vandekerchove, D., Wybo, I., Immerseel, F. V., Heyndrickx, M., Collard, J. M., Ducatelle, R., Haesebrouck, F.: Characterization of Salmonella isolates from captive lizards. Vet Microbiol 110, 285-291 (2005).

29. Le Hello, S., Brisabois, A., Accou-Demartin, M., Josse, A., Marault, M., Francart, S., Da Silva, N. J., Weill, F. X.: Foodborne outbreak and non-motile Salmonella enterica variant, France. Emerg Infect Dis 18, 132-134 (2012).

30. Bugarel, M., Granier, S. A., Bonin, E., Vignaud, M. L., Roussel, S., Fach, P., Brisabois, A.: Genetic diversity in monophasic $(1,4,[5], 12: 1:-$ and 1,4,[5],12:-:1,2) and innon-motile $(1,4,[5], 12:-:-)$ variants of Salmonella enterica S. Typhimurium. Food Res Int 46, 1016-1024 (2012).

31. Yang, X., Wu, Q., Zhang, J., Huang, J., Guo, W., Cai, S.: Prevalence and characterization of monophasic Salmonella serovar 1,4,[5],12:i:- of food origin in China. PLoS One 10, e0137967 (2015).

32. Mitchell, M. A., Shane, S. M., Nevarez, J., Pesti, D., Sanchez, S., Wooley, R. E., Ritchies, B.: Establishing a Salmonella-free iguana, Iguana iguana, model using enrofloxacin. In Proceeding of the VIII Annual Conference, Association Reptilian and Amphibian Reptiles, 2001, pp. 189-190.

33. Pezzella, C., Ricci, A., Di Giannatale, E., Luzzi, I., Carattoli, A.: Tetracycline and streptomycin resistance genes, transposons, and plasmids in Salmonella enterica isolates from animals in Italy. Antimicrob Agents Chemother 48, 903-908 (2004).

34. Miko, A., Pries, K., Schroeter, A., Helmuth, R.: Molecular mechanisms of resistance in multidrug-resistant serovars of Salmonella enterica isolated from foods in Germany. J Antimicrob Chemother 56, 1025-1033 (2005).

35. Durante-Mangoni, E., Grammatikos, A., Utili, R., Falagas, M. E.: Do we still need the aminoglycosides? Int J Antimicrob Agents 33, 201-205 (2009).

36. Yu, J., Schneider, T.: Tigecycline challenge triggers sRNA production in Salmonella enterica serovar Typhimurium. BMC Microbiol 12, 195 (2012).

37. Hentschke, M., Christner, M., Sobottka, I., Aepfelbacher, M., Rohde, H.: Combined ramR mutation and presence of a Tn1721-associated tet(A) variant in a clinical isolate of Salmonella enterica serovar Hadar resistant to tigecycline. Antimicrob Agents Chemother 54, 1319-1322 (2010).

38. Livermore, D. M., Warner, M., Mushtaq, S., Doumith, M., Zhang, J., Woodford, N.: What remains against carbapenem-resistant Enterobacteriaceae? Evaluation of chloramphenicol, ciprofloxacin, colistin, fosfomycin, minocycline, nitrofurantoin, temocillin and tigecycline. Int J Antimicrob Agents 37, 415-419 (2011).

39. Sun, Y., Cai, Y., Liu, X., Bai, N., Liang, B., Wang, R.: The emergence of clinical resistance to tigecycline. Int J Antimicrob Agents 41, 110-116 (2013).

40. EFSA and ECDC (European Food Safety Authority and European Centre for Disease Prevention and Control): EU summary report on antimicrobial resistance in 
zoonotic and indicator bacteria from humans, animals and food in 2013. EFSA J 13, 4036 (2015).

41. Proroga, Y. T., Capuano, F., Carullo, M. R., La Tela, I., Capparelli, R., Barco, L., Pasquale, V.: Occurrence and antimicrobial resistance of Salmonella strains from food of animal origin in southern Italy. Folia Microbiol 61, 21-27 (2016).

42. Ziech, R. E., Lampugnani, C., Perin, A. P., Sereno, M. J., Sfaciotte, R. A., Viana, C., Soares, V. M., de Almeida Nogueira Pinto, J. P., Dos Santos Bersot, L.: Multidrug resistance and ESBL-producing Salmonella spp. isolated from broiler processing plants. Braz J Microbiol 47, 191-195 (2016).

43. Murphy, D., Oshin, F.: Reptile-associated salmonellosis in children aged under 5 years in South West England. Arch Dis Child 100, 364-365 (2015). 